International Journal of Electronics and Communication Engineering and Technology (IJECET)

Volume 12, Issue 1, January-April 2021, pp. 1-7. Article ID: IJECET_12_01_001

Available online at https://iaeme.com/Home/issue/IJECET?Volume $=12 \&$ Issue $=1$

ISSN Print: 0976-6464 and ISSN Online: 0976-6472

DOI: 10.34218/IJECET.12.1.2021.001

\title{
DESIGN AND PERFORMANCE ANALYSIS OF CASCODE OPERATIONAL TRANSCONDUCTANCE AMPLIFIER FOR LOW POWER ANALOG APPLICATIONS
}

\author{
Sarah Khwaja \\ Bachelor of Engineering (Gold Medalist), Jamia Millia Islamia, India
}

Dr. Shamimul Qamar

Professor of Computer Science and Engineering, College of Sciences and Arts, Dhahran Al Janub, King Khalid university, Abha, Saudi Arabia

\begin{abstract}
The evolution of the microelectronics industry is distinguished by the raising level of integration and complexity. It aims to decrease exponentially the minimum feature sizes used to design integrated circuits. The cost of design is a great problem to the continuation of this evolution. Senior designer's knowledge and skills are required to ensure a good design of analogue integrated circuit. This paper presents an optimized methodology to cascode operational transconductance amplifier (OTA) design. The challenge in the design of op-amps is the scaling down of the supply voltage and transistor channel length with each generation of CMOS technologies. As CMOS technology continues to evolve, the supply voltages are decreasing while at the same time, the transistor threshold voltages are remaining relatively constant. The decrease in the inherent gain of the nano-CMOS transistors is also of great concern. The design is done for different parameters like gain, bandwidth, phase margin and slew rate etc to optimize MOS transistor sizing. The designed cascode OTA achieves a DC gain of satisfied range and an optimum unity-gain frequency.
\end{abstract}

Keywords: CMOS IC design, Cascode OTA design methodology, optimization.

Cite this Article: Sarah Khwaja and Shamimul Qamar, Design and Performance Analysis of Cascode Operational Transconductance Amplifier for Low Power Analog Applications, International Journal of Electronics and Communication Engineering and Technology, 12(1), 2021, pp. 1-7.

https://iaeme.com/Home/issue/IJECET?Volume=12\&Issue=1 


\section{INTRODUCTION}

The evolution of the microelectronics industry is distinguished by the raising level of integration and complexity. It aims to decrease exponentially the minimum feature sizes used to design integrated circuits. The cost of design is a great problem to the continuation of this evolution. Senior designer's knowledge and skills are required to ensure a good analogue integrated circuit design. To fulfil the given requirements, the designer must choose the suitable circuit architecture, although different tools partially automating the topology synthesis appeared in the past [1]-[4].The optimization becomes an important method; a heuristic process was developed in [5]. Designing high-performance baseband analog circuits is still a hard task toward reduced supply voltages and increased frequency. The Operational Transconductance Amplifier (OTA) is a basic element in this type of circuit whether switched capacitors technique is kept for ADC design. Our target was to design a cascode OTA circuit insight of Sigma Delta analog-to-digital converter design using for wide band radio applications. This paper is organized as follows. An optimum Architecture of the folded cascode OTA was introduced in section II and its function was analyzed to extract the circuit performances. Section III describes an approach for designing this OTA, clarifies specific design issues, and results. While section IV provides concluding remarks.

\section{OPTIMUM TOPOLOGY -OTA ARCHITECTURE}

Several fundamental issues exist when selecting an optimal architecture for the operational transconductance amplifier. This choice aimed both at large gain and large bandwidth performances. In order to achieve high gain, the differential telescopic topologies can be used. The telescopic architecture is a better candidate for a low power consumption and low noise OTA. The performance of simple OTA is limited by its input and output voltage swing. To overcome these limits of simple OTA and have an improved performance a Folded Cascode OTA is used [6]-[12].

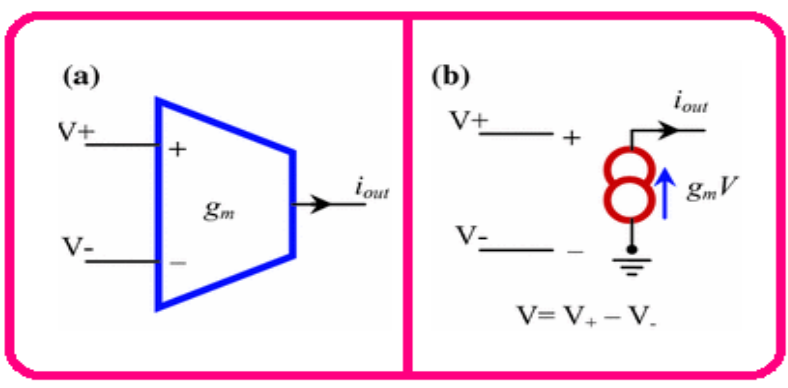

Figure 1 Basic OTA and its Equivalent Circuit

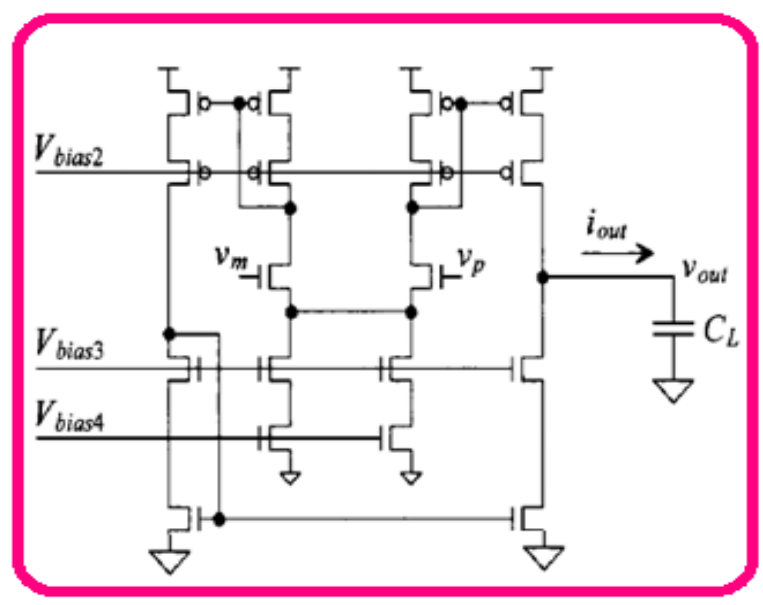

Figure 2 Cascode OTA circuit (Higher output Resistance) 


\section{CMOS CASCODE OTA}

The operational transconductance amplifier (OTA) is used as basic building block in many switched capacitor filters. OTA is basically an op-amp without an output buffer and can only drive capacitive loads. An OTA is an amplifier where all nodes are low impedance except the input and output nodes. A useful feature of OTA is that its transconductance can be adjusted by the bias current. Filters made using the OTA can be tuned by changing the bias current Ibias. Two practical concerns when designing an OTA for filter applications are the input signal amplitude and the parasitic input/output capacitances. Large signals cause the OTA gain to become non-linear. The external capacitance should be large compared to the input or output parasitic of the OTA. This limits the maximum frequency of a filter built with an OTA and causes amplitude or phase errors. These errors can usually be reduced with proper selection of Ibias. The performance of simple OTA is limited by its input and output voltage swing. To overcome these limits of simple OTA and have an improved performance a Folded Cascode OTA is used. The name "folded cascode" comes from folding down $n$-channel cascode active loads of a diff-pair and changing the MOSFETs to p-channels [13]-[29].

\section{MODELLING AND SIMULATION OF COTA}

The Output Voltage of the OTA is given by:

$$
\text { Vout=GmVinRo }
$$

The "Unity gain frequency" of the OTA is:

$$
\mathrm{Fu}=2 \pi \mathrm{gm} / \mathrm{C}_{\mathrm{L}}
$$

Transconductance $(\mathrm{Gm})$ is computed as:

$$
\mathrm{Gm}=2 \pi \mathrm{GBWC}_{\mathrm{L}}
$$

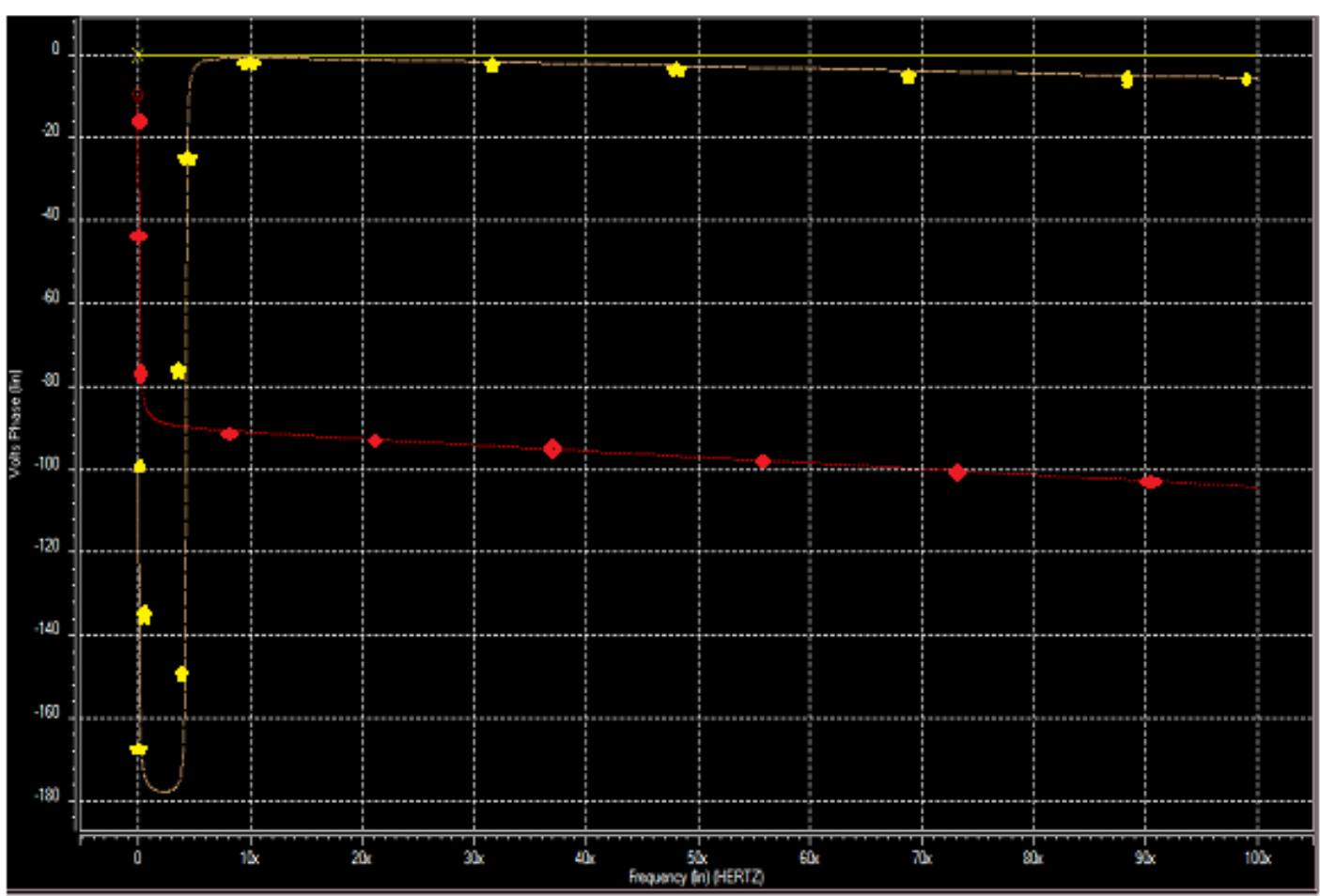

Figure 3 AC Analysis of Cascode Operational Transconductanse 


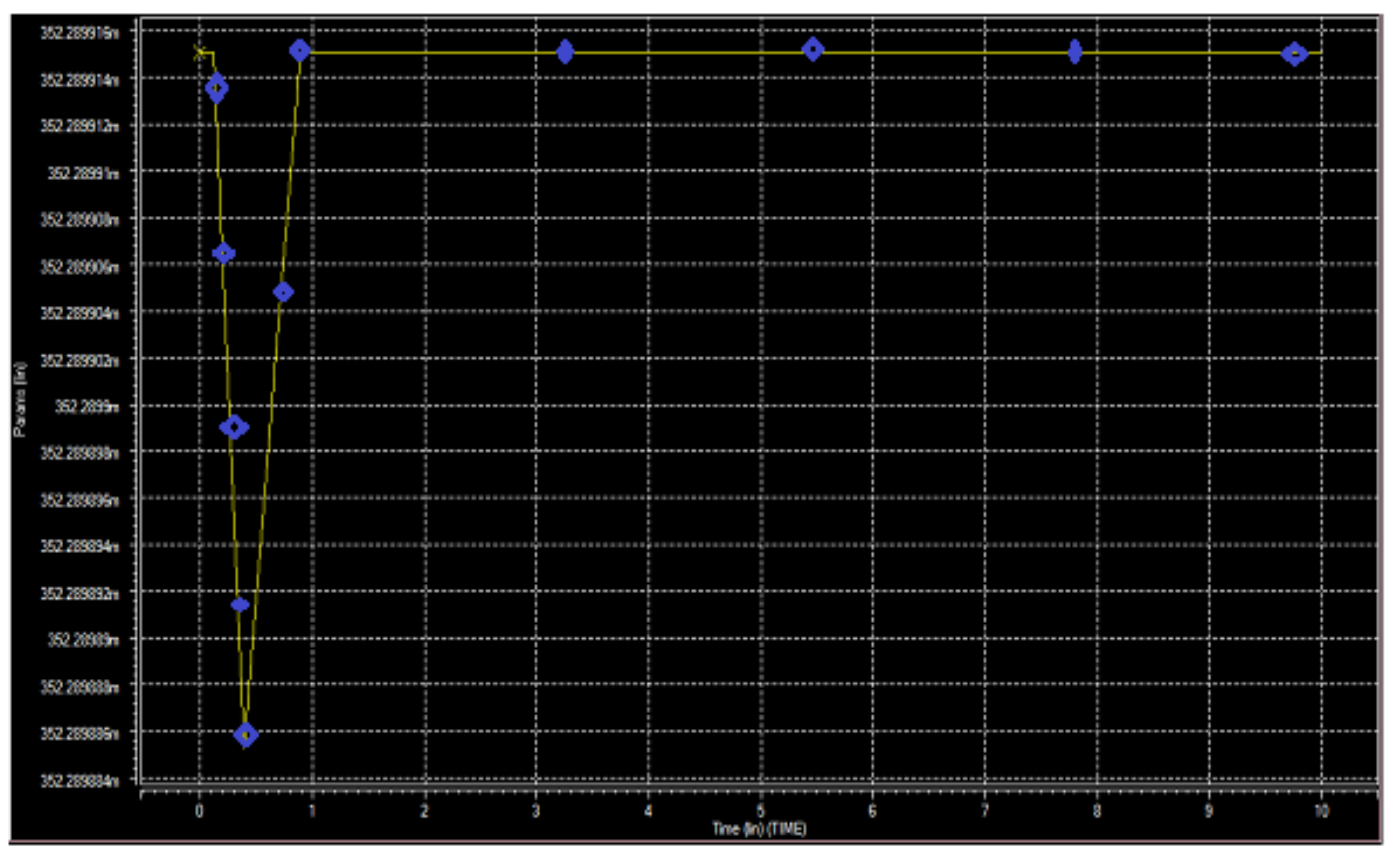

Figure 4 Transient for Average Power Dissipation of Cascode OTA

Table 1 Performance Measuring Parameters of COTA

\begin{tabular}{|l|l|l|}
\hline S. No. & Parameter & Value \\
\hline $\mathbf{1}$ & DC Gain in $\mathrm{dB}$ & $2.4661 \mathrm{E}+01$ \\
\hline $\mathbf{2}$ & Band width in $\mathrm{GHz}$ & $1.6091 \mathrm{E}+06$ \\
\hline $\mathbf{3}$ & Phase Margin in degree & $9.0558 \mathrm{E}+01$ \\
\hline $\mathbf{4}$ & Slew Rate $\mathrm{V} / \mu \mathrm{s}$ & $2.0285 \mathrm{E}-05$ \\
\hline $\mathbf{5}$ & Average Power in $\mu \mathrm{W}$ & $1.4908 \mathrm{E}-04$ \\
\hline $\mathbf{6}$ & Output Resistance $\mathrm{K} \Omega$ & $5.3949 \mathrm{k}$ \\
\hline $\mathbf{7}$ & Unity Gain Frequency in $\mathrm{dB}$ & $3.0947 \mathrm{E}+07$ \\
\hline
\end{tabular}

Table 2 Variation of Performance Measuring Parameters of COTA

\begin{tabular}{|c|c|c|c|c|c|c|}
\hline S.No. & Parameters & $0.9 \mathrm{~V}$ & $1 \mathrm{~V}$ & $1.2 \mathrm{~V}$ & $1.4 \mathrm{~V}$ & $1.6 \mathrm{~V}$ \\
\hline 1 & $\begin{array}{l}\text { DC Gain in } \\
\mathrm{dB}\end{array}$ & $2.4400 \mathrm{E}+01$ & $2.4661 \mathrm{E}+01$ & $2.4992 \mathrm{E}+01$ & $2.5065 \mathrm{E}+01$ & $2.4619 \mathrm{E}+01$ \\
\hline 2 & $\begin{array}{l}\text { Bandwidth } \\
\text { in } \mathrm{GHz}\end{array}$ & $1.6076 \mathrm{E}+06$ & $1.6091 \mathrm{E}+06$ & $1.6384 \mathrm{E}+0$ & $1.7134 \mathrm{E}+06$ & $1.9122 \mathrm{E}+06$ \\
\hline 3 & $\begin{array}{l}\text { Phase } \\
\text { Margin }\end{array}$ & $9.0700 \mathrm{E}+01$ & $9.0558 \mathrm{E}+01$ & $9.0354 \mathrm{E}+01$ & $9.0248 \mathrm{E}+01$ & $9.0330 \mathrm{E}+01$ \\
\hline 4 & Slew Rate & $1.8112 \mathrm{E}-05$ & $2.0285 \mathrm{E}-05$ & $2.1830 \mathrm{E}-05$ & $2.3162 \mathrm{E}-05$ & $1.9579 \mathrm{E}-05$ \\
\hline 5 & $\begin{array}{l}\text { Average } \\
\text { Power }\end{array}$ & $1.2968 \mathrm{E}-04$ & $1.4908 \mathrm{E}-04$ & $1.8739 \mathrm{E}-04$ & $2.2834 \mathrm{E}-04$ & $2.7295 \mathrm{E}-04$ \\
\hline 6 & $\begin{array}{l}\text { Output } \\
\text { Resistance }\end{array}$ & $5.5557 \mathrm{k}$ & $5.3949 \mathrm{k}$ & $5.1118 \mathrm{k}$ & $4.8560 \mathrm{k}$ & $4.5873 \mathrm{k}$ \\
\hline 7 & $\begin{array}{l}\text { Unity Gain } \\
\text { Frequency }\end{array}$ & $3.0072 \mathrm{E}+07$ & $3.0947 \mathrm{E}+07$ & $3.2770 \mathrm{E}+07$ & $3.4659 \mathrm{E}+07$ & $3.6730 \mathrm{E}+07$ \\
\hline
\end{tabular}




\section{RESULTS \& DISCUSSIONS}

The cascode operational transconductance amplifier circuit is designed for optimum structural device parameters namely bandwidth, output resistance, power dissipation etc in addition to the selection of operating supply voltages. By studying the effect of parameter various with supply voltage as depicted in table 2 , it was found that for best performance, the supply voltage must be set around $0.9 \mathrm{~V}$. The lowering of supply supply voltage decreases the power consumption due to proportional scaling but it also affects the circuit slew rate and average power. This is due to lower output swing and pronounced effect of parasitic which deteriorates the bandwidth of the amplifier. As expected, almost all other parameters improved.

\section{CONCLUSION}

Studying the effect of parameter variations with supply voltage, it was found that for best performance, the supply voltage must be set around $0.9 \mathrm{~V}$. The lowering of supply voltage decreases the power consumption due to proportional scaling but it also affects the circuit slew rate and settling time. This is due to lower output swing and pronounced effect of parasitic which deteriorates the bandwidth of the amplifier. As expected, almost all other parameters improve but due to lower swing, robustness deteriorates. The supply voltage must better performance of the cascade operational transconductance amplifier (COTA) in CMOS technology. With the variation of the voltage, parameters value are affected, DC gain \& Bandwidth increases, O/P resistance \& Power dissipation decreases, Slew rate is varied in the different value of voltage. Hence the minimum supply voltage is better in the Cascode Operational Transconductance amplifier (OTA) in CMOS technology

\section{REFERENCES}

[1] M Nizamuddin, Divisha Sharma, "FinFET based Operational Transconductance Amplifier for Low Power Applications", International Journal of Computer Sciences and Engineering, Vol.-7, Issue-5, May 2019.

[2] Åkerberg, Dag, and Kare Mossberg, -A Versatile Active RC Building Block with Inherent Compensation for the Finite Bandwidth of the Amplifier, IEEE Transactions on Circuits and Systems, vol. 21, no. 1 pp. 75-78, 1974.

[3] S. A. Loan, M. Nizamuddin et.al., - Band Performance Carbon Nanotube Based Cascode Operational Transconductance Amplifiers\|, World Congress on Engineering, Vol 1, July 2 $-4,2014$.

[4] M. Nizamuddin, S. A. Loan, et.al., -Design, Simulation and The Comparative Analysis of CNTFET Based Multistage Operational Amplifiersll, Journal of Nanoelectronics and Optoelectronics, Vol-12, 2017.

[5] S. A. Loan, M. Nizamuddin et.al., -Design and Comparative Analysis of Band Performance Carbon Nanotube-Based Cascode Operational transconductance amplifiers, NANO: World Scientific Publisher, Vol. 10, No. 3, 2015.

[6] M. Nizamuddin, S. A. Loan, et.al., - Design, Simulation and Comparative Analysis of CNT based Cascode Cascode Operational Transconductance Amplifiers, Volume 26, Number 39, 02 , Nanotechnology, IOP Publishing Ltd ,October 2015.

[7] S. A. Loan et al., Design of a novel Band Gain Carbon Nanotube Based Cascode Operational Transconductance Amplifier, Proc. IMECS PP. 797-800, 2014. 
[8] M. Nizamuddin, et.al., Carbon Nanotube Based Three Stage Operational Amplifiers, A Simulation Studyll, Journal of Materials Today Proceedings, Volume 3, Issue 2, Pages 449453, 2015.

[9] Fahad Ali Usmani, et.al., Carbon Nanotube Field Effect Transistors for High Performance Analog Applications: An Optimum Design Approachll, Microelectronics Journal, 41, 2010.

[10] J.Deng, H.S.P.Wong, A Compact SPICE Model for Carbon Nanotube Field Effect Transistors Including Non-Idealities and its Application Part II:\| IEEE Transactions on Electron Devices 54, 2007.

[11] Sarah khwaja, Design and Simulation of High Performance Low Power Analog Filters for Biomedical Applications at $90 \mathrm{~nm}$ Technology Nodell, International Journal of Multidisciplinary Educational Research, Volume 8, Issue 12(2), December, 2019.

[12] J.Appenzeller, Carbon Nanotubes for High Performance Electronicsl, Proceedings of the IEEE 96(2), 2008.

[13] Sarah Khwaja, Design and Simulation of High Performance High Pass Filter at $45 \mathrm{~nm}$ Technology Node, International Journal of Innovative Research in Electrical, Electronics, Instrumentation and Control Engineering Vol. 7, Issue 7, July 2019.

[14] Sarah Khwaja, —Simulation Study of High Performance Low Pass filter at Nanoscale, International Journal of Advanced Research in Computer and Communication Engineering Vol. 8, Issue 8, Aug 2019.

[15] Sarah Khwaja, -Design and Performance Analysis of Low Power Band Pass Filter at 32 $\mathrm{nm}$ Technologyll, International Journal of Innovative Research in Electrical, Electronics, Instrumentation and Control Engineering Vol. 7, Issue 9, September 2019.

[16] Faisal Bashir, Sajad A Loan, M Nizamuddin, et.al., — A Novel High Performance Nano Scaled Dopingless Lateral PNP Transistor on Silicon on Insulator, Proceedings of the International Multi Conference of Engineers and Computer Scientists, 2014.

[17] Sarah Khwaja, -Design and Performance Analysis of Low Power Band Stop Filter,International Journal of Advance Research in Engineering and Technology, 10 (6), 2019, pp 16-21.

[18] Sajad A Loan, Faisal Bashir, M Rafat, M Nizamuddin, Asim M Murshid, Abdul Rahman M Alamoud, Shuja A Abbasi, - A Novel High Performance Nanoscaled Dual Oxide Doping Less Tunnel Field Effect Transistor, Proceedings of the World Congress on Engineering, 2014.

[19] M Nizamuddin, -Design \& Performance Analysis of Instrumentation Amplifier at Nanoscalell, Int J Adv Res Ideas Innov Technol, Volume 3, Issue 1, Pages 793-798, 2017.

[20] Muhammad Masud, et.al., —Design of Voltage Mode Electronically Tunable First Order All Pass Filter in 0.7 V 16 nm CNFET Technologyl, Electronics MDPI, Open Access Journal, 2019.

[21] Sherif H. K. Embabi, Edgar Sanchez- Sinencio, "Multistage Amplifier Topologies with Nested Gm-C Compensation,” IEEE J. Solid- State Circuits, vol. 32, pp. 2000-2011, Dec. 1997. 
Design and Performance Analysis of Cascode Operational Transconductance Amplifier for Low Power Analog Applications

[22] Sarah Khwaja, Design and Simulation of Advanced Buffered Amplifier for Low Power Biomedical Applications, International Journal of Advanced Research in Engineering and Technology (IJARET), 11 (1), 2020, pp 23-29.

[23] Sarah khwaja, Simulation study of Advanced Inverting Amplifier for Low Power Biomedical Applicationsll, International Journal of Multidisciplinary Educational Research, Volume 8, Issue 11(4), November, 2019.

[24] S. A. Loan et al., Design of a novel Band gain carbon nanotube based Cascode Operational transconductance amplifier, Proc. IMECS (2014) pp. 797-800.

[25] Sarah khwaja, Design and Simulation of High Performance Low Power Voltage Mode OTA-C Universal Filter for Biomedical Applications at 90nm Technology Node, International Journal of Innovative Research in Electrical, Electronics, Instrumentation and Control Engineering Vol. 8, Issue 4, April 2020.

[26] Ramón González et al. ," The flipped voltage follower: a useful cell for low-voltage lowpower circuit design," IEEE transactions on circuits and systems-I: VOL. 52, NO. 7, JULY 2005.

[27] Antonio J. Lopez-Marlin, et al., "Low-voltage low-power wideband CMOS current conveyors based on the flipped voltage follower," Circuits and Systems, 2003. ISCAS '03. Proceedings of the 2003 International Symposium on Volume 1, 25-28 May 2003 Page(s): I-801 - I-804 vol.1.

[28] J.Ramirez-Angulo, R.G.Carvajal, A.Torralba, J. Galan, A.P. Vega-Leal, and J. Tombs,” The flipped voltage follower: a useful cell for low-voltage low-power circuit design," in Proc. Int. Symp. Circuits and Systems, ISCAS, vol. 3, May 2002, pp. 615-618. 